\title{
Análise da utilização de cerâmica vermelha como adsorvente na remoção do corante têxtil Direct Blue de uma solução aquosa
}

\author{
Application of red clay as adsorbent in the \\ removal of textile dye Direct Blue of \\ an aqueous solution
}

\begin{abstract}
Alex Barbosa Campos Silva ${ }^{1}$, Ricardo Mauricio de Freitas Andrade ${ }^{1}$, Flavio Bentes Freire ${ }^{2}$, André Nagalli ${ }^{2}$, Karina Querne de Carvalho ${ }^{2}$, Fernando Hermes Passig ${ }^{3}$, Cristiane Kreutz ${ }^{4}$
\end{abstract}

\footnotetext{
${ }^{1}$ Programa de Pós-Graduação em Engenharia Civil - PPGEC/UTFPR CEP: 81.280-340, Curitiba, PR

${ }^{2}$ Departamento Acadêmico de Construção Civil - DACOC/UTFPR CEP: 81.280-340, Curitiba, PR

${ }^{3}$ Departamento Acadêmico de Química e Biologia - DAQBI/UTFPR CEP: 81.280-340, Curitiba, PR

${ }^{4}$ Departamento Acadêmico de Ambiental - DAAMB/UTFPR CEP: 87301-899, Campo Mourão, PR e-mail: barbosa.alexc@gmail.com; ri_mafrean@yahoo.com.br; flaviofreire@utfpr.edu.br; nagalli@utfpr.edu.br; kaquerne@utfpr.edu.br; fhpassig@utfpr.edu.br; ckreutz@utfpr.edu.br
}

\section{RESUMO}

A adsorção tem sido estudada como alternativa para tratamento de efluentes têxteis contendo corantes tóxicos, carcinogênicos, mutagênicos e que interferem no equilíbrio dos ecossistemas aquáticos ao serem lançados no ambiente sem adequado tratamento prévio. Este problema é agravado pois até $50 \%$ da quantidade de corante aplicado nas etapas de tingimento e de lavagem não se fixa às fibras dos tecidos. $\mathrm{O}$ objetivo deste estudo foi avaliar a remoção de cor de uma solução aquosa contendo o corante direct blue, na concentração inicial de $5 \mathrm{~g} / \mathrm{L}$, através da adsorção em cerâmica vermelha. Para isto, foram selecionadas as faixas de diâmetro de $1,21 \mathrm{~mm}$ a $2,4 \mathrm{~mm}$ e de $2,41 \mathrm{~mm}$ a $4,8 \mathrm{~mm}$ e as massas de 200,250 e $300 \mathrm{~g}$ do adsorvente para cada faixa. Os ensaios foram conduzidos sob agitação constante de $120 \mathrm{rpm}$ a temperatura ambiente, com duração total de 5 horas, para avaliar o desempenho da adsorção a partir dos valores obtidos para remoção de cor. Além disto, os resultados foram ajustados aos modelos cinéticos de pseudo-primeira ordem e pseudo-segunda ordem de Lagergren. Em todas as configurações experimentais avaliadas, o equilíbrio se deu após a primeira hora de ensaio e as remoções de cor variaram de 98,2\% a 99,5\%. Do ponto de vista da capacidade de adsorção por massa de adsorvente, os melhores resultados foram verificados com massa de $200 \mathrm{~g}$ do adsorvente. Constatou-se ainda que os resultados foram moderadamente mais efetivos na faixa de menor de diâmetro com desempenho $0,5 \%$ superior à faixa de maiores diâmetros. $\mathrm{O}$ modelo cinético de pseudo-segunda ordem se ajustou melhor aos resultados experimentais quando comparado ao de pseudoprimeira ordem. Foi possível concluir através da pesquisa que a cerâmica de argila adquirida na Região Metropolitana de Curitiba foi um material efetivo na remoção do corante Direct Blue de uma solução aquosa.

Palavras-chave: Adsorção, direct blue, cerâmica vermelha, cinética.

\begin{abstract}
Adsorption has been studied as an alternative to the treatment of textile effluents containing toxic, carcinogenic, mutagenic dyes that also interfere in the equilibrium of aquatic ecosystems when discharged in the environment without proper previous treatment. This problem is as $50 \%$ of the amount of dye applied in the steps of dyeing and laundering does not attach to the fabric fibers. The aim of this study was to evaluate color removal from an aqueous solution containing blue direct dye at an initial concentration of $5 \mathrm{~g} / \mathrm{L}$, by the adsorption on ceramic clay. For this purpose, the ranges of diameter of $1.21 \mathrm{~mm}$ to $2.4 \mathrm{~mm}$ and $2.41 \mathrm{~mm}$ to $4.8 \mathrm{~mm}$ and the quantities mass of 200,250 and $300 \mathrm{~g}$ of the adsorbent were selected for each range. Assays were carried out under constant agitation of $120 \mathrm{rpm}$ at room temperature, with a total duration of 5 hours, to evaluate the performance of the adsorption from the values obtained for color removal. Furthermore, the results were adjusted to the kinetic pseudo-first order and pseudo-second order models of Lagergren. In all the experimental settings evaluated, the equilibrium was reached after the first hour of the assay and the color
\end{abstract}


removals varied from $98.2 \%$ to $99.5 \%$. Regarding the adsorption capacity by the mass of the adsorbent, the best results were verified with mass of $200 \mathrm{~g}$ of the adsorbent. It was also found that results were moderately effective at the lowest range of diameter $(0.5 \%$ higher than the performance of larger diameters). The pseudosecond order kinetics model fits better to the experimental data when compared to the pseudo-first order. It was possible to conclude from the research that the red clay acquired in the Metropolitan Region of Curitiba was an effective material in the removal of the Direct Blue dye from an aqueous solution

Keywords: Adsorption, direct blue, red clay, kinetic.

\section{INTRODUÇÃO}

Do ponto de vista ambiental, o setor têxtil se caracteriza por um elevado consumo de água, bem como pela geração de resíduos sólidos, emissões atmosféricas e efluentes líquidos que possuem grande potencial de contaminação ambiental $[1,2,3,4]$.

Os principais problemas ligados aos efluentes líquidos estão relacionados à elevada quantidade de carga orgânica, cor, toxicidade e salinidade [5]. No que diz respeito à cor, sabe-se que vários tipos de corantes (naturais, reativos, ácidos, catiônicos, dentre outros) podem ser utilizados na indústria têxtil, principalmente nas etapas de tingimento e lavagem. Aproximadamente 10.000 corantes sintéticos são utilizados extensivamente como insumos industriais, principalmente na indústria têxtil e de tinturaria [6].

De acordo com Chakraborty et al. [7], por exemplo, para colorir $1 \mathrm{~kg}$ de algodão com corantes reativos, são necessários entre 70 e $150 \mathrm{~L}$ de água, sendo que $80 \%$ deste volume podem ser descartados como efluente. Estas substâncias se configuram em uma importante parte dos problemas de poluição, sobretudo pela estimativa de que, para alguns tipos de corantes, até $50 \%$ da quantidade aplicada às fibras dos tecidos não se fixa a elas, formando posteriormente as águas residuárias [5].

Muitos corantes são tóxicos, mutagênicos [4] e, além disso, efluentes com elevada cor absorvem a luz nos corpos receptores, interferindo no equilíbrio dos ecossistemas aquáticos $[4,8]$. Os corantes "AZO”, por exemplo, sistematicamente investigados pela comunidade cientifica, e que produzem aminas aromáticas, comprovadamente carcinogênicas, foram banidos pelo setor têxtil a partir de 2003, seguindo a recomendação da Comunidade Europeia [9]. Ainda não há no Brasil alguma proibição formal quanto ao emprego de corantes "AZO". Porém, vários desses corantes já não tem sido utilizados por fabricantes responsáveis, sobretudo em virtude das sanções europeias [10].

Os processos biológicos $[4,11,12,13,14,15]$, usualmente com custos atrativos, são efetivos na remoção de parcela considerável da matéria orgânica biodegradável desses efluentes, porém podem apresentar algumas desvantagens. Conforme mencionado por Robinson et al. [16], "lodos ativados convencional e outros tipos de reatores biológicos são falhos na remoção satisfatória de cor e de micropoluentes".

Deste modo, a complexa composição dos efluentes têxteis requer a aplicação de métodos físicoquímicos, isolados ou combinados [1], inclusive com os processos biológicos. Dentre as possibilidades, destaca-se a adsorção [17, 7].

Conforme analisado por Conceição et al. [9], uma vertente mais atual identificada nos estudos de adsorção envolve a avaliação de materiais adsorventes "alternativos", ou seja, que se credenciem como opção aos materiais já consagrados (como o carvão ativado, por exemplo), possibilitando custos mais atrativos. Os autores avaliaram a adsorção em cerâmica de argila como pós-tratamento de um efluente têxtil sintético contendo azul índigo. Resíduos cerâmicos também foram utilizados como adsorventes de uma solução contendo o corante azul de metileno, e os resultados, tanto para estudos em batelada [18], quanto para estudos em colunas de adsorção [19], foram positivos e indicaram a viabilidade do material.

Dentro deste contexto, este trabalho propõe uma avaliação da adsorção (com cerâmica vermelha) no tratamento de uma solução com corante têxtil.

\section{MATERIAIS E MÉTODOS}

\subsection{Preparação da solução com corante}

O corante orgânico Direct Blue 151 (DB151) foi escolhido para os experimentos por ser muito utilizado no tingimento industrial de tecidos ou fibras de algodão, linho, sisal, rami, rayon-viscose e combinações destes, e também pelo fato de sua comercialização não ser restrita, facilitando sua aquisição.

O DB151 foi solubilizado em água potável em um agitador magnético com aquecimento (sob 
temperatura de $90{ }^{\circ} \mathrm{C}$ ), resultando em uma solução "estoque" com concentração de 5 g.L $\mathrm{L}^{-1}$ e pH neutro.

\subsection{Material Adsorvente}

A utilização da cerâmica vermelha como material adsorvente foi baseada no trabalho de Conceição et al. [9]. Ao justificarem a escolha, os autores mencionaram os resultados efetivos dos diferentes tipos de argila como adsorventes, e presumiram que a cerâmica de argila também poderia proporcionar um desempenho similar. Mais detalhes sobre o experimento desses autores seguem no capítulo de resultados. Este material foi coletado em uma olaria da região metropolitana do município de Curitiba (PR), proveniente de tijolos de barro da construção civil (já queimados) descartados pelo setor de controle da qualidade.

Amostras do material adsorvente foram moídas no aparelho de Abrasão Los Angeles a $30 \mathrm{rpm}$ de giro (50 Hz), conforme procedimento descrito na NBR 6465 [20], e em seguida o material, que apresentava granulometria heterogênea, foi peneirado no agitador de peneiras eletromagnético para seleção de duas faixas de diâmetro pré estabelecidas por Conceição et al. [9]: 1,21 mm a 2,4 mm e 2,41 mm a 4,8 mm (Figura 1), as quais foram denominadas Faixa 01 e Faixa 02, respectivamente.

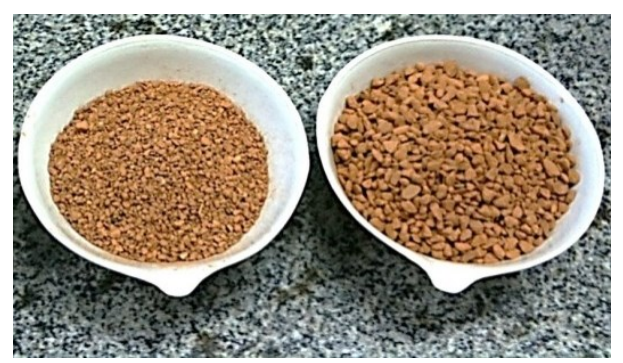

Figura 1: Cerâmica vermelha: faixas de diâmetro de 1,21 mm a 2,4 mm (esquerda); e 2,41 a 4,8 mm (direita).

Antes dos ensaios de adsorção as amostras foram submetidas à secagem na temperatura de $100 \pm 5{ }^{\circ} \mathrm{C}$ em estufa durante $24 \mathrm{~h}$. Após a secagem, as amostras foram armazenadas em dessecador para posterior utilização.

\subsection{Ensaios de Adsorção}

Os ensaios foram conduzidos sob agitação constante de 120 rpm e temperatura ambiente.

Para cada faixa de diâmetro avaliada foram utilizados três jarros, aos quais um volume de $1000 \mathrm{~mL}$ da solução com o corante foi colocado em contato com $200 \mathrm{~g}, 250 \mathrm{~g}$ e $300 \mathrm{~g}$ de adsorvente, respectivamente, totalizando seis ensaios.

Cada ensaio teve duração total de $5 \mathrm{~h}$, sendo que alíquotas de $15 \mathrm{~mL}$ foram retiradas em intervalos de tempo de $1 \mathrm{~h}$. Antes das análises de remoção de cor, e para separação das fases, as amostras foram centrifugadas a $2200 \mathrm{rpm}$ durante $5 \mathrm{~min}$.

A remoção de cor foi obtida a partir de leituras de absorbância [21, 22, 23, 24, 25, 26]. Em suma, o procedimento padrão consiste em identificar o comprimento de onda mais apropriado para as leituras. Para tanto, uma amostra da solução "bruta" com o DB151 (antes dos ensaios de adsorção) foi submetida à crescentes comprimentos de onda (em espectrofotômetro Varian, modelo Cary 50 uv-vis) e foram registradas as respectivas absorbâncias. O pico de absorbância foi obtido para um valor de comprimento de onda de $537 \mathrm{~nm}$. Assim, as remoções de cor foram obtidas através de medições de absorbância em espectrofotômetro marca FEMTO, modelo 600Plus, no comprimento de onda mencionado, a partir da Equação 1.

$$
R C(\%)=100 x\left(\frac{A B S_{i}-A B S_{f}}{A B S_{i}}\right)
$$

Em que: RC representa a remoção de cor (em porcentagem); $\mathrm{ABS}_{\mathrm{i}}$ é a absorbância inicial; $\mathrm{ABS}_{\mathrm{f}}$ é a absorbância final da amostra.

A concentração residual do corante DB151 na solução aquosa foi determinada de acordo com a Equação 2. 


$$
\frac{C_{t}}{C_{i}}=\frac{A B S_{t}}{A B S_{i}}
$$

Em que: $C_{t}$ é a concentração do corante em um tempo qualquer de amostragem (g/L); $C_{i}$ é a concentração inicial de corante $(5 \mathrm{~g} / \mathrm{L}) ; \mathrm{ABS}_{\mathrm{t}}$ é a absorbância da amostra retirada em um tempo t; $\mathrm{ABS}_{\mathrm{i}}$ é a absorbância inicial.

A equação 2 foi estabelecida em virtude da solução utilizada nos ensaios ser composta exclusivamente por água potável e o corante. Desta maneira, foi possível estabelecer uma relação direta entre a remoção de cor e a concentração do corante [26].

\subsection{Cinética de Adsorção}

A cinética de adsorção foi avaliada com base nos resultados da remoção do corante da solução aquosa em diferentes intervalos de tempo, para as três massas de adsorvente avaliadas ( $200 \mathrm{~g}, 250 \mathrm{~g}$ e $300 \mathrm{~g})$ bem como as duas faixas de diâmetro das partículas de cerâmica vermelha.

Foram utilizados os modelos cinéticos de pseudo-primeira ordem e de pseudo-segunda ordem para a previsão das constantes cinéticas de adsorção.

A equação cinética da pseudo-primeira ordem [27] é amplamente utilizada para determinar a cinética de adsorção de corantes [28]. Neste modelo, a velocidade de adsorção pode ser determinada por uma expressão de velocidade de pseudo-primeira ordem dada por Lagergren para adsorção em sistema líquidosólido baseada na capacidade do sólido. A velocidade de remoção do adsorbato em função do tempo é diretamente proporcional à diferença na concentração de saturação e ao número de sítios ativos disponíveis do sólido. A equação cinética de Lagergren é a mais utilizada para adsorção de um adsorbato de uma solução aquosa [29].

A constante cinética de adsorção de pseudo-primeira ordem de Lagergren, k, do DB151 na cerâmica vermelha foi calculada de acordo com a Equação 3.

$$
\log \left(q_{e}-q_{t}\right)=\log \left(q_{e}\right)-\frac{k_{1}}{A B S_{i}} \cdot t
$$

Em que: $\mathrm{q}_{\mathrm{e}}$ e $\mathrm{q}_{\mathrm{t}}(\mathrm{mg} / \mathrm{g})$ correspondem, respectivamente, as capacidades de adsorção no equilíbrio e em um tempo qualquer $\mathrm{t}(\mathrm{min}) ; \mathrm{k}_{1}$ é a constante cinética de pseudo-primeira ordem de adsorção $\left(\mathrm{min}^{-1}\right)$, e representa o coeficiente angular da reta que representa o gráfico de $\log \left(\mathrm{q}_{\mathrm{e}}-\mathrm{q}_{\mathrm{t}}\right)$ em função do tempo.

A capacidade de adsorção em um tempo qualquer (q), em $\mathrm{mg} / \mathrm{g}$, pode ser calculada a partir da equação 4, baseada no balanço de massa.

$$
q=\frac{\left(C_{0}-C_{t}\right) \cdot V}{m}
$$

Em que $\mathrm{C}_{0}$ é a concentração inicial do soluto $(\mathrm{mg} / \mathrm{L}) ; \mathrm{C}_{\mathrm{t}}$ é a concentração do soluto em um tempo $\mathrm{t}$ $(\mathrm{mg} / \mathrm{L}) ; \mathrm{V}$ é o volume da solução a ser tratada $(\mathrm{L}) ; \mathrm{m}$ é a massa de adsorvente $(\mathrm{g})$.

No procedimento para ajuste da cinética de pseudo-segunda ordem [30] foi estabelecido que a velocidade da reação é vinculada à quantidade do soluto adsorvido na superfície do adsorvente e da quantidade adsorvida no equilíbrio, conforme a Equação 5.

$$
\frac{t}{q_{t}}=\frac{1}{k_{2} \cdot q_{e}^{2}}+\frac{1}{q_{e}} \cdot t
$$

Em que: $\mathrm{q}_{\mathrm{e}}$ e $\mathrm{q}_{\mathrm{t}}(\mathrm{mg} / \mathrm{g})$ correspondem, respectivamente, as capacidades de adsorção no equilíbrio e em um tempo qualquer $\mathrm{t}(\mathrm{min}) ; \mathrm{k}_{2}$ é constante cinética de pseudo-segunda ordem de adsorção ( $\mathrm{g} / \mathrm{mg}$.min). Com relação à equação da reta, o coeficiente angular representa a relação $\left(1 / \mathrm{q}_{\mathrm{e}}\right)$ sendo assim possível obter o valor de qe, e o coeficiente linear representa a relação $\left(1 / \mathrm{k}_{2} \cdot \mathrm{q}_{\mathrm{e}}{ }^{2}\right)$, possibilitando a obtenção da constante $\mathrm{k}_{2}$.

A taxa de adsorção inicial (em mg/g.min) pode ser calculada quando o tempo tende a zero, conforme Equação 6.

$$
h=k_{2} \cdot q_{e}^{2}
$$


A partir do modelo cinético de melhor ajuste, foi possível estabelecer uma estimativa das concentrações adsorvidas em qualquer tempo, com validade dentro do período estudado.

\section{RESULTADOS E DISCUSSÃO}

\subsection{Ensaios de adsorção}

Os resultados dos ensaios de adsorção em termos de concentração remanescente no tempo $\left(\mathrm{C}_{t}\right)$, da concentração adsorvida $\left(\mathrm{C}_{\mathrm{ads}}\right)$ e da remoção de cor $(\mathrm{RC})$, para os diâmetros e as massas avaliados estão apresentados na Tabela 1.

Tabela 1: Resultados dos ensaios de adsorção.

\begin{tabular}{|c|c|c|c|c|c|c|c|}
\hline \multicolumn{4}{|c|}{ Faixa $01(1,21$ a $2,4 \mathrm{~mm})$} & \multicolumn{4}{|c|}{ Faixa $02(2,41$ a $4,8 \mathrm{~mm})$} \\
\hline Massa (g) & Tempo (h) & $\mathrm{C}_{\mathrm{t}}(\mathrm{g} / \mathrm{L})$ & $\mathrm{RC}(\%)$ & Massa (g) & Tempo (h) & $\mathrm{C}_{\mathrm{t}}(\mathrm{g} / \mathrm{L})$ & $\mathrm{RC}(\%)$ \\
\hline \multirow{6}{*}{200} & 0 & 5,00 & 0,0 & \multirow{6}{*}{200} & 0 & 5,00 & 0,0 \\
\hline & 1 & 0,22 & 95,7 & & 1 & 0,66 & 86,7 \\
\hline & 2 & 0,16 & 96,9 & & 2 & 0,19 & 96,2 \\
\hline & 3 & 0,14 & 97,1 & & 3 & 0,16 & 96,9 \\
\hline & 4 & 0,07 & 98,7 & & 4 & 0,14 & 97,2 \\
\hline & 5 & 0,05 & 98,9 & & 5 & 0,09 & 98,2 \\
\hline \multirow{6}{*}{250} & 0 & 5,00 & 0,0 & \multirow{6}{*}{250} & 0 & 5,00 & 0,0 \\
\hline & 1 & 0,18 & 96,4 & & 1 & 0,20 & 95,9 \\
\hline & 2 & 0,09 & 98,3 & & 2 & 0,11 & 97,8 \\
\hline & 3 & 0,08 & 98,4 & & 3 & 0,11 & 97,9 \\
\hline & 4 & 0,06 & 98,8 & & 4 & 0,10 & 98,0 \\
\hline & 5 & 0,03 & 99,5 & & 5 & 0,07 & 98,6 \\
\hline \multirow{6}{*}{300} & 0 & 5,00 & 0,0 & \multirow{6}{*}{300} & 0 & 5,00 & 0,0 \\
\hline & 1 & 0,15 & 97,0 & & 1 & 0,14 & 97,3 \\
\hline & 2 & 0,11 & 97,8 & & 2 & 0,13 & 97,4 \\
\hline & 3 & 0,10 & 98,1 & & 3 & 0,10 & 98,1 \\
\hline & 4 & 0,09 & 98,1 & & 4 & 0,08 & 98,5 \\
\hline & 5 & 0,08 & 98,4 & & 5 & 0,07 & 98,6 \\
\hline
\end{tabular}

Constata-se que a maior parcela da remoção de cor ocorreu dentro da primeira hora de todos os ensaios e o equilíbrio da adsorção foi atingido logo após este período, independentemente da granulometria e da massa de resíduos de cerâmica de argila utilizadas. Na primeira hora, com exceção do ensaio com $200 \mathrm{~g}$ de adsorvente (na Faixa 02 de diâmetro), cuja remoção de cor atingiu 86,7\%, em todos os outros ensaios houve remoções acima de $95 \%$.

Os resultados para a Faixa 01 e para Faixa 02 de diâmetro, no que diz respeito ao decaimento da concentração de corante ao longo do tempo, para as três massas de adsorvente avaliadas, estão apresentados nas Figuras 2 e 3, respectivamente.

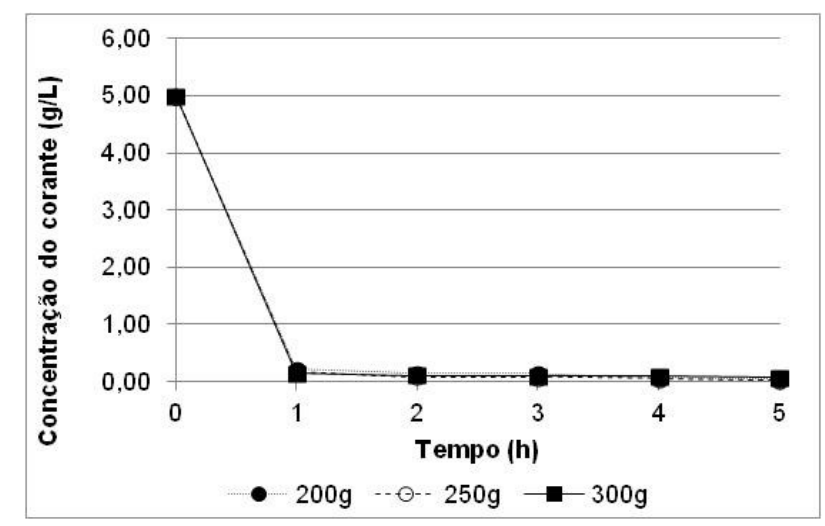

Figura 2: Decaimento da concentração de corante no tempo para a Faixa 01 de diâmetro, para as massas de $200 \mathrm{~g}, 250 \mathrm{~g}$ e $300 \mathrm{~g}$. 
Na Faixa 01 de diâmetro, as eficiências de remoção de cor foram de 98,9\% para $200 \mathrm{~g}$ de massa de adsorvente, $99,5 \%$ para a massa de $250 \mathrm{~g}$, sendo este inclusive o maior desempenho individual entre todos os seis ensaios, e 98,4\% empregando uma massa de 300 g. Na Faixa 02 de diâmetro as eficiências de remoção de cor foram de $98,2 \%$, com $200 \mathrm{~g}$ de adsorvente, e $98,6 \%$ tanto utilizando $250 \mathrm{~g}$ quanto $300 \mathrm{~g}$ de adsorvente.

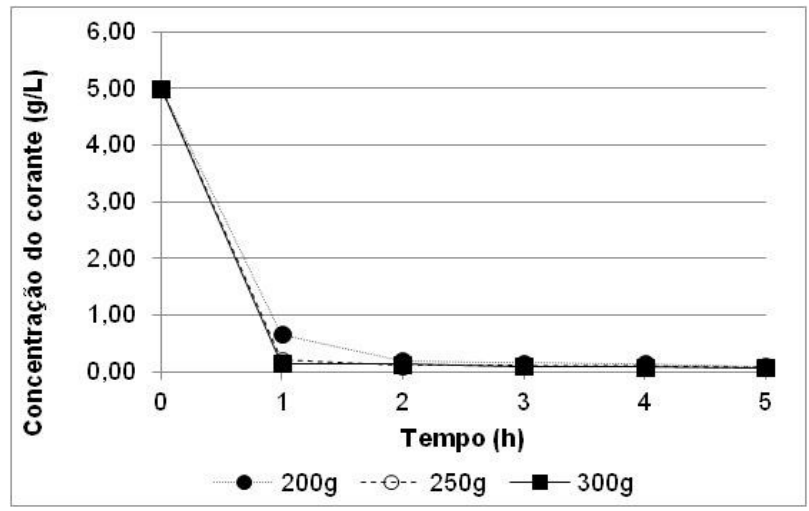

Figura 3: Decaimento da concentração de corante no tempo para a Faixa 02 de diâmetro, para as massas de $200 \mathrm{~g}, 250 \mathrm{~g}$ e $300 \mathrm{~g}$.

Quanto à influência da massa de adsorvente na remoção do DB151, para as duas faixas de diâmetros avaliadas, as médias de remoção de cor para $200 \mathrm{~g}, 250 \mathrm{~g}$ e $300 \mathrm{~g}$ foram, respectivamente, 98,6\%, 99,0\% e $98,5 \%$.

Embora o melhor desempenho tenha sido obtido a partir de $250 \mathrm{~g}$ de adsorvente na Faixa 01 de diâmetro, ressalta-se que as eficiências ficaram muito próximas, o que estatisticamente permite considerar os desempenhos equivalentes. A maior diferença entre as eficiências foi de 1,3\%, valor que está dentro do próprio erro experimental, pois a precisão do espectrofotômetro na leitura das absorbâncias (de 0,3\%, fornecida pelo fabricante no manual do equipamento) propaga um erro de até $1,1 \%$ na remoção de cor, de acordo com a teoria dos erros [31].

$$
\sigma_{\mathrm{RC}}=\sqrt{\left[\left(\frac{\mathrm{ABS}_{\mathrm{F}}}{\mathrm{ABS}_{\mathrm{i}}^{2}}\right)^{2} \cdot \sigma_{\mathrm{i}}^{2}+\left(\frac{1}{\mathrm{ABS}_{\mathrm{i}}}\right)^{2} \cdot \sigma_{\mathrm{F}}^{2}\right] \cdot 100}
$$

Em que: $\sigma_{\mathrm{RC}}$ se refere ao erro vinculado ao cálculo da remoção de cor; $\mathrm{ABS}_{\mathrm{i}}$ e $\mathrm{ABS}_{\mathrm{F}}$ são, respectivamente os valores lidos para absorbância inicial e final; e $\sigma_{\mathrm{i}}$ e $\sigma_{\mathrm{F}}$ são os desvios vinculados à leitura de absorbância inicial e final, respectivamente.

É importante observar que se trata de um erro em módulo. Ou seja, ao se levar em consideração que este erro poderá ser para mais ou para menos, há um erro total de $2,2 \%$ vinculado somente à remoção de cor. Há ainda os erros relacionados à obtenção do volume de solução (balão volumétrico) e da massa de adsorvente (balança), à centrifugação, dentre outros.

Com os resultados, observou-se que uma diferença de até 50\% na massa de adsorvente não apresentou efeito significativo na remoção de cor. Nesse aspecto, é possível então considerar que a massa de $200 \mathrm{~g}$ de adsorvente proporcionou os melhores resultados, uma vez que o adsorvente, ao assimilar o corante, necessitará de um tratamento posterior para um gerenciamento adequado.

Conceição et al. [9] pesquisaram a remoção de cor de uma solução com o corante índigo blue através da adsorção em cerâmica de argila, comparando o desempenho com o carvão ativado, um material adsorvente já consolidado na literatura. Os autores observaram que a remoção de cor foi maior quanto maior foi a massa utilizada de adsorvente. Além disso, foi bem mais evidente a diferença de desempenho com relação às massas avaliadas. A partir de ensaios com 360 minutos de duração, a maior eficiência alcançada foi de $97 \%$, similar ao valor encontrado nesta pesquisa, e estava vinculada a uma massa de $200 \mathrm{~g} / \mathrm{L}$ de adsorvente, enquanto uma remoção de $82 \%$, e portanto $18 \%$ menor, foi verificada ao utilizarem uma massa de $150 \mathrm{~g} / \mathrm{L}$ de adsorvente. $\mathrm{O}$ desempenho foi próximo ao do carvão ativado, mas ressalta-se que com uma massa de $70 \mathrm{~g}$ (por litro de solução) deste último material já foi obtida uma remoção de cor de $99 \%$.

Ainda no que se refere à pesquisas que avaliaram o desempenho de adsorventes alternativos, na 
Tabela 2 estão apresentados outros estudos mais recentes relacionados com a remoção de cor de corantes têxteis pela técnica de adsorção. As eficiências apresentadas se referem às configurações experimentais que proporcionaram os melhores resultados.

Tabela 2: Estudos envolvendo adsorção de corantes têxteis utilizando adsorventes não convencionais.

\begin{tabular}{|c|c|c|c|}
\hline Referência & Corante & Adsorvente & Eficiência (\%) \\
\hline $\begin{array}{l}\text { Shirzad-Siboni et al. } \\
\text { (2014) [32] }\end{array}$ & azul reativo & resíduos de conchas & 99,99 \\
\hline $\begin{array}{l}\text { Bayrak e Usgor (2013) } \\
\text { [33] }\end{array}$ & remazol preto $\mathrm{B}$ & casca de laranja & 99,40 \\
\hline $\begin{array}{l}\text { Kadam et al. (2013) } \\
\text { [34] }\end{array}$ & vermelho 5B & bagaço de cana de açúcar & 91,0 \\
\hline \multirow{3}{*}{$\begin{array}{c}\text { Baseri et al. (2011) } \\
\text { [17] }\end{array}$} & verde de malaquita & \multirow{3}{*}{$\begin{array}{l}\text { Thevetia peruviana } \\
\text { (“Chapéu de Napoleão) }\end{array}$} & 98,5 \\
\hline & violeta cristal & & 97,8 \\
\hline & rodamina $\mathrm{B}$ & & 97,3 \\
\hline $\begin{array}{c}\text { Cardoso et al. (2011) } \\
\text { [35] }\end{array}$ & remazol preto $\mathrm{B}$ & pinho de Araucária & 55,6 \\
\hline
\end{tabular}

Conceição et al. [36] também avaliaram a remoção de cor da mesma solução com o corante índigo blue através da adsorção em bagaço de cana, e obtiveram na melhor configuração experimental uma eficiência de $85 \%$, a partir de uma massa de $30 \mathrm{~g}$ de adsorvente por litro de efluente, e 360 minutos de duração total do ensaio.

A casca de ovo, por exemplo, após uma preparação prévia (tratamento químico) foi avaliada por Elkady et al. [37] como adsorvente do corante Remazol Vermelho. Os autores verificaram que o tempo de equilíbrio foi de cerca de 180 minutos, e que as maiores remoções (acima de 95\%) foram atingidas a partir das menores concentrações iniciais do corante, indicando que este parâmetro tem importância fundamental nas taxas de adsorção.

Vasques et al. [38] aproveitaram o próprio lodo de processo de tratamento de efluentes têxteis (de uma indústria na região de Blumenau - SC) para estudos de adsorção do corante reativo vermelho. O lodo adsorvente foi obtido após ser submetido a etapas de ativação térmica e química e para as melhores condições adsortivas, nas concentrações iniciais de 100 e $500 \mathrm{mg} / \mathrm{L}$, as remoções de cor foram de $99,73 \%$ e $88,57 \%$, respectivamente. Neste caso, menores concentrações iniciais de solvente proporcionaram as maiores remoções.

Verifica-se através da literatura que o estudo de adsorventes não convencionais é bastante proeminente e que os resultados desta pesquisa corroboram a potencialidade da cerâmica vermelha.

Com relação a influência do diâmetro das partículas na remoção de cor, os resultados para as três massas de adsorvente avaliadas, com a discriminação das faixas de diâmetro, estão apresentados nas Figuras 4,5 e 6.

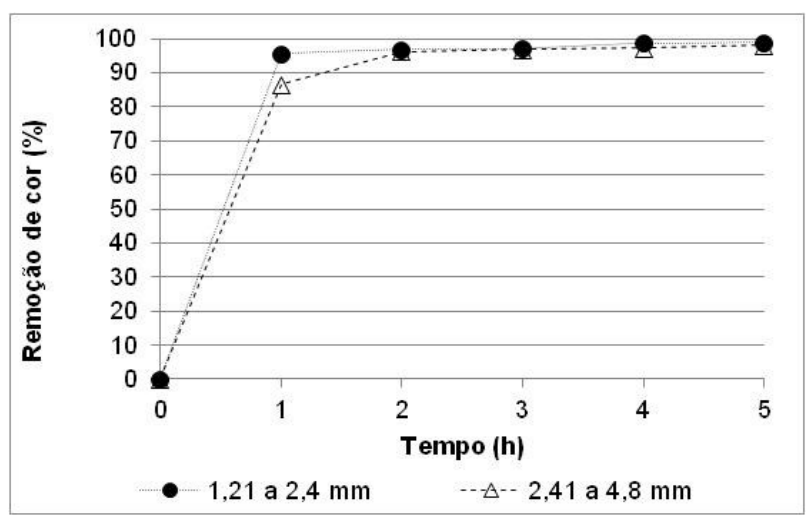

Figura 4: Remoção de cor para $200 \mathrm{~g}$ de massa de adsorvente. 


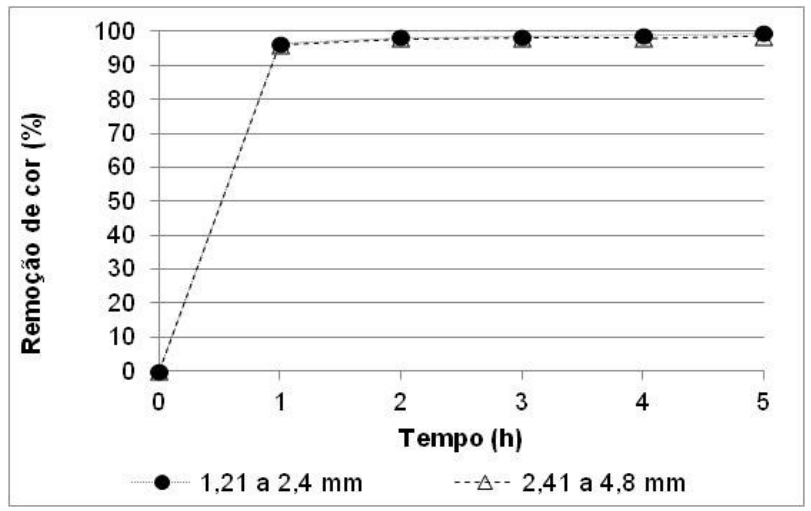

Figura 5: Remoção de cor para $250 \mathrm{~g}$ de massa de adsorvente.

Nota-se pelas Figuras 4 e 5 que na Faixa 01 de granulometria foram obtidas as melhores remoções de cor, tanto para a massa de $200 \mathrm{~g}(98,9 \%)$ quanto para a de $250 \mathrm{~g}(99,5 \%)$ de adsorvente, em comparação a Faixa 02 (98,2\% e 98,6\%, respectivamente).

No que se refere a massa de $300 \mathrm{~g}$ (Figura 6) houve pequena superioridade na remoção de cor para a Faixa $02(98,6 \%)$ em relação à Faixa 01 (98,4\%). Dessa forma, ao se analisarem as remoções médias para as duas faixas de diâmetro, a remoção média de cor para a Faixa 01 foi de 98,9\%, valor 0,5\% superior em relação a média da Faixa 02, que foi de 98,4\%.

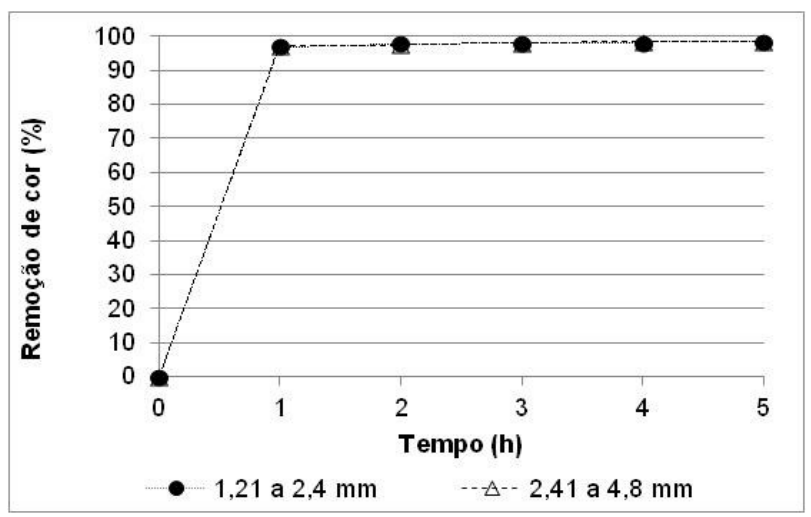

Figura 6: Remoção de cor para $300 \mathrm{~g}$ de massa de adsorvente.

Chakraborty et al. [7] estudaram a adsorção de um corante têxtil básico (violeta cristal) em serragem de madeira e observaram que a máxima capacidade de adsorção aumentou com o decréscimo do tamanho da partícula. Os autores justificaram que "partículas menores proporcionam maior área superficial por unidade de massa, resultando em um ganho de adsorção".

Neste trabalho, com uma remoção de cor média $0,5 \%$ superior da Faixa 01 em relação à Faixa 02 , não houve uma aumento considerável da adsorção para diâmetros médios menores. Provavelmente, a quantidade de adsorvente em excesso (já discutida anteriormente) fez com que a área superficial não se configurasse em um parâmetro significativo.

\subsection{Cinética da adsorção}

Na Figura 7 tem-se o gráfico para o melhor resultado obtido para a cinética de pseudo-primeira ordem, em termos de correlação, referente a uma massa de $200 \mathrm{~g}$ de adsorvente com diâmetros situados na Faixa 02. 


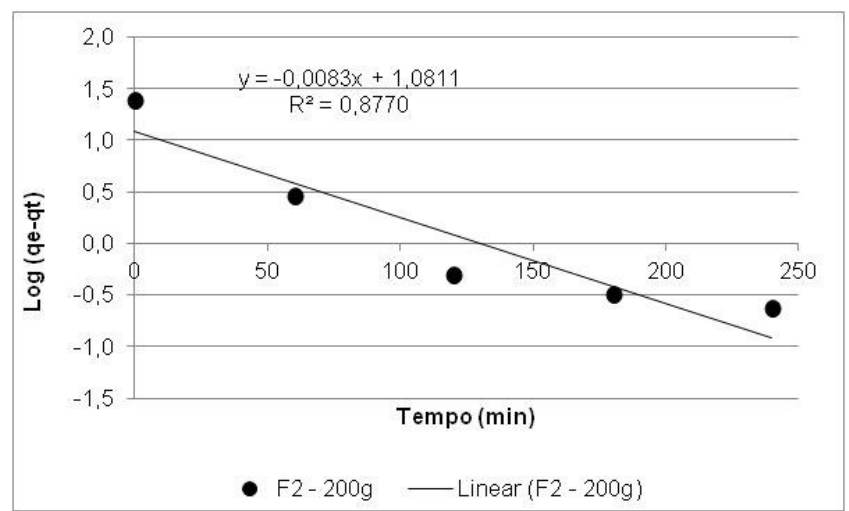

Figura 7: Resultados para a cinética de pseudo-primeira ordem referentes a uma massa de $200 \mathrm{~g}$ de adsorvente e Faixa 02 de diâmetro.

No que diz respeito ao estudo da cinética de adsorção, o ajuste dos dados para pseudo-primeira ordem resultou em correlações entre 0,8770 e 0,7170 .

Com a análise da Figura 7, bem como das correlações obtidas, verifica-se que o modelo de pseudoprimeira ordem não foi adequado para uma obtenção acurada das constantes cinéticas. Assim não se configura em alternativa apropriada para representar o experimento. Em razão das correlações indicarem que o ajuste de pseudo-segunda ordem foi mais representativo, optou-se por não apresentar os resultados de pseudo-primeira ordem para as massas de $250 \mathrm{~g}$ e $300 \mathrm{~g}$.

Dessa forma, nas Figuras 8, 9 e 10 estão apresentados os resultados do ajuste de pseudo-segunda ordem para as massas de 200 g, 250 g e 300 g, respectivamente, para as duas faixas de diâmetro. Nos gráficos estão apresentadas as equações lineares de ajuste, bem como os coeficientes de correlação obtidos.

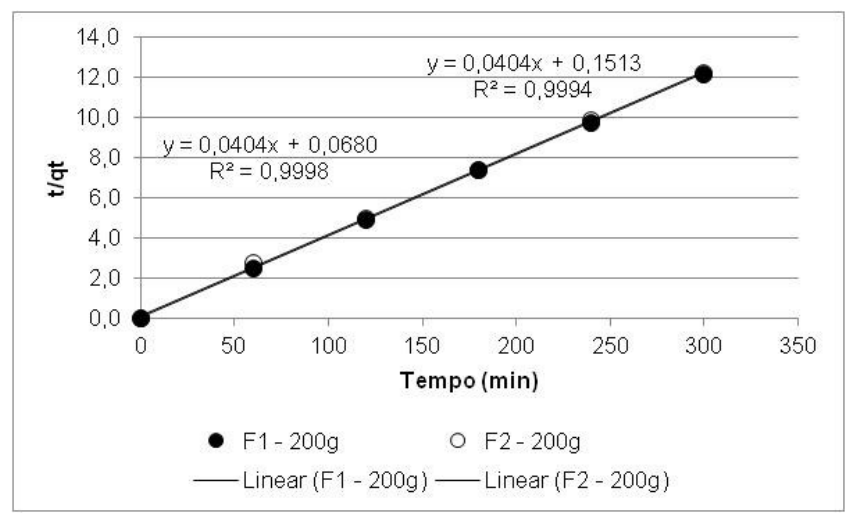

Figura 8: Ajuste cinético de pseudo-segunda ordem para a massa de $200 \mathrm{~g}$ de adsorvente.

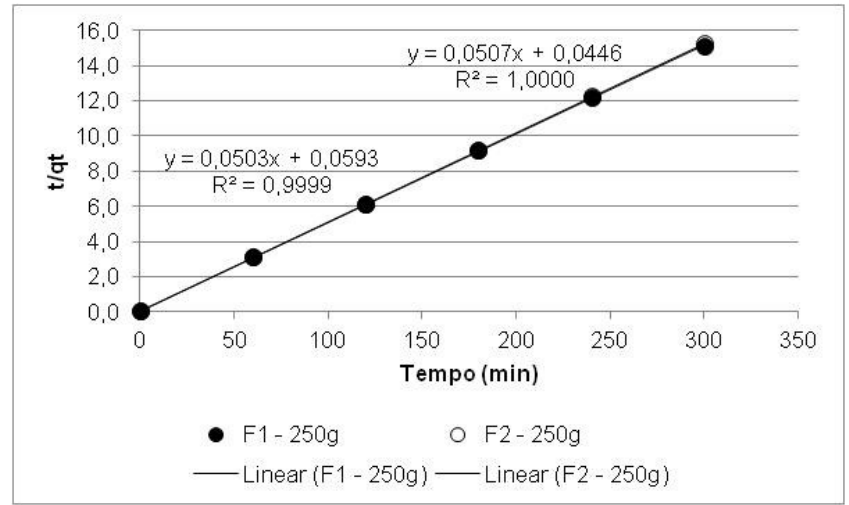

Figura 9: Ajuste cinético de pseudo-segunda ordem para a massa de $250 \mathrm{~g}$ de adsorvente. 


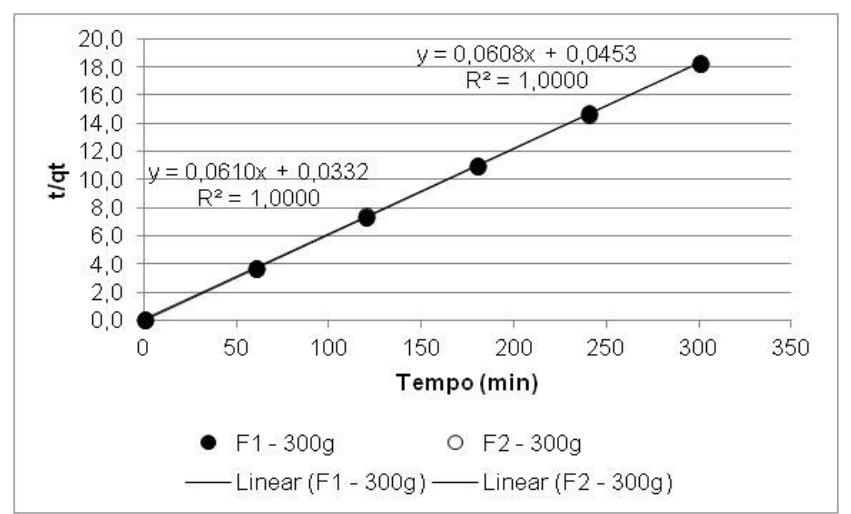

Figura 10: Ajuste cinético de pseudo-segunda ordem para a massa de $300 \mathrm{~g}$ de adsorvente.

Na Tabela 3 estão apresentados os valores para $\mathrm{k}_{2} \mathrm{e} \mathrm{h}$, respectivamente a constante cinética de pseudosegunda ordem de adsorção (g/mg.min) e da taxa de adsorção inicial (em mg/g.min) para os Faixas 01 e 02 de diâmetros e as massas avaliados, bem como as correlações alcançadas no ajuste.

Tabela 3: Resumo do estudo cinético para as faixas de diâmetros e massas avaliados.

\begin{tabular}{ccccc}
\hline Ensaio & qe (mg/g) & $\mathbf{k}_{\mathbf{2}}$ (g/mg.min) & h (mg/g.min) & $\mathbf{R}^{\mathbf{2}}$ \\
\hline F01 - 200 g & 24,78 & 0,02394 & 14,70 & 0,9998 \\
\hline F02-200 g & 24,74 & 0,01080 & 6,61 & 0,9994 \\
\hline F01 - 250 g & 19,90 & 0,04261 & 16,87 & 0,9999 \\
\hline F02 - 250 g & 19,71 & 0,05765 & 22,41 & 1,0000 \\
\hline F01-300 g & 16,41 & 0,11183 & 30,10 & 1,0000 \\
\hline F02-300 g & 16,45 & 0,08163 & 22,08 & 1,0000 \\
\hline
\end{tabular}

Os maiores valores tanto para capacidade inicial de adsorção quanto para a constante cinética foram obtidos para o ensaio na Faixa 01 de diâmetros, com $300 \mathrm{~g}$ de adsorvente. Nos gráficos da cinética, os pontos experimentais e as linhas de tendência ajustadas estão praticamente sobrepostos. Todos os ajustes apresentaram elevada correlação, indicando a reprodutibilidade da cinética de pseudo-segunda ordem para as condições experimentais da pesquisa.

A importância do estudo da cinética não se concentra exclusivamente no estudo isolado das constantes obtidas. Essa comparação é frequentemente difícil uma vez que os resultados estão vinculados à condições experimentais muito particulares. Por exemplo, Valdivelan e Kumar [28] ao estudarem a adsorção do azul de metileno, obtiveram para a constante inicial de adsorção (h) valores situados entre 0,18 e $0,77 \mathrm{mg} / \mathrm{g} . \mathrm{min}$, valores bem inferiores aos obtidos nesta pesquisa. No entanto, o adsorvente utilizado foi a casca de arroz.

Através do estudo da cinética é possível estabelecer uma relação entre a massa de adsorvato incorporada ao adsorvente $\left(\mathrm{q}_{\mathrm{t}}\right.$, em $\left.\mathrm{mg} / \mathrm{g}\right)$ em um tempo qualquer. Sendo assim, na Figura 11 estão apresentados os resultados para a estimativa da massa de corante adsorvida por massa de adsorvente $\left(\mathrm{q}_{\mathrm{t}}\right)$ obtidos a partir das equações provenientes do ajuste de pseudo-segunda ordem (Figuras 8, 9 e 10). Como os coeficientes de correlação resultaram elevados (para três dos seis ensaios foi obtida correlação máxima ao se levar em consideração quatro algarismos significativos), optou-se por não introduzir no gráfico os valores experimentais (Figura 11). 


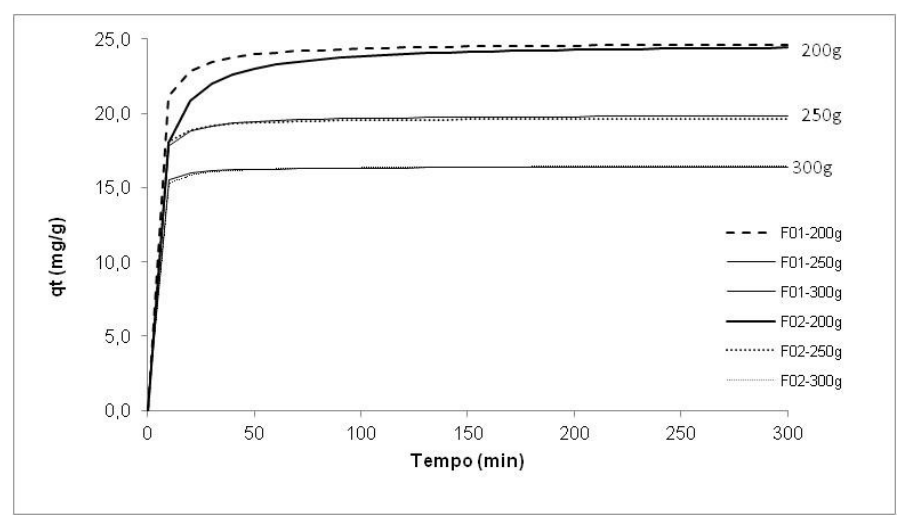

Figura 11: Estimativa da massa de corante assimilada por massa de adsorvente para as massas de 200, 250 e $300 \mathrm{~g}$ para as faixas de diâmetro 01 e 02 .

A partir da análise da Figura 11, fica evidente o comentário feito anteriormente, de que do ponto de vista ambiental a massa de $200 \mathrm{~g}$ proporcionou os melhores resultados, uma vez que foi a que mais assimilou o corante no período estudado.

Para corroborar a qualidade do ajuste, na Tabela 4 estão contidos os valores de capacidade de adsorção $\left(\mathrm{q}_{\mathrm{t}}\right)$ previstos e comparados com os obtidos experimentalmente, para os tempos após 120 e 300 min.

Tabela 4: Comparação entre $\mathrm{q}_{\mathrm{t}}$ experimental e $\mathrm{q}_{\mathrm{t}}$ estimado para cinética de pseudo-segunda ordem para os tempos de 120 e $300 \mathrm{~min}$.

\begin{tabular}{|c|c|c|c|c|}
\hline \multirow[t]{2}{*}{ Ensaio } & \multicolumn{2}{|c|}{$\mathrm{q}_{\mathrm{t}}$ experimental (mg/g) } & \multicolumn{2}{|c|}{$\mathrm{q}_{\mathrm{t}}$ estimado (mg/g) } \\
\hline & $t=120 \mathrm{~min}$ & $t=300 \mathrm{~min}$ & $t=120 \mathrm{~min}$ & $t=300 \mathrm{~min}$ \\
\hline $\mathrm{F} 01-200 \mathrm{~g}$ & 24,22 & 24,74 & 24,43 & 24,64 \\
\hline F02-200 g & 24,04 & 24,54 & 23,99 & 24,43 \\
\hline $\mathrm{F} 01-250 \mathrm{~g}$ & 19,65 & 19,89 & 19,70 & 19,82 \\
\hline $\mathrm{F} 02-250 \mathrm{~g}$ & 19,57 & 19,71 & 19,57 & 19,66 \\
\hline $\mathrm{F} 01-300 \mathrm{~g}$ & 16,30 & 16,40 & 16,33 & 16,38 \\
\hline $\mathrm{F} 02-300 \mathrm{~g}$ & 16,23 & 16,43 & 16,35 & 16,41 \\
\hline
\end{tabular}

Em uma série de trabalhos analisados também se constatou que cinética de pseudo-primeira ordem apresentou resultados menos acurados que a de pseudo-segunda ordem [37, 39, 40].

Ho e McKay [29] apresentaram uma revisão da literatura relacionada com adsorção de efluentes líquidos contendo corantes têxteis orgânicos ou íons metálicos e mencionaram que desde 1984 mais de 70 sistemas foram reportados, sendo que em mais de 43 desses foi constatada maior correlação no ajuste cinético de pseudo-primeira ordem. Os autores escolheram 11 desses trabalhos para novos testes cinéticos e verificaram que em todos eles as maiores correlações atingidas foram para a cinética de pseudo-segunda ordem.

Convém enfatizar que o modelo de pseudo-segunda ordem surgiu em 1996 [30] e que todos os estudos de Ho e McKay [29] aos quais a cinética de pseudo-primeira ordem havia sido a mais satisfatória foram publicados anteriormente a esta data.

Valdivelan e Kumar [28] afirmaram que “...o modelo de pseudo-segunda ordem tem sido amplamente utilizado para sistemas de adsorção devido à sua boa representação dos dados experimentais para a maior parte dos sistemas de adsorvente/adsorvato".

\section{CONCLUSÕES}

Em todas as configurações experimentais avaliadas, as remoções de cor foram efetivas, com resultados muito similares, mesmo para diferenças de até $50 \%$ na massa de adsorvente.

A Faixa 01 de diâmetro, compreendida entre 1,21 e 2,4 mm proporcionou resultados ligeiramente superiores aos da Faixa 02, com diâmetros entre 2,41 e 4,8 mm. No estudo da cinética, os dados experimentais se ajustaram melhor a uma cinética de pseudo-segunda ordem, uma vez que foram obtidas correlações superiores às do ajuste de cinética de pseudo-primeira ordem. 
Através do presente estudo foi possível constatar que a cerâmica vermelha pode ser usada como adsorvente na remoção do corante Direct Blue 151 (DB151) de uma solução aquosa.

\section{BIBLIOGRAFIA}

[1] DASGUPTA, J., SIKDER, J., CHAKRABORTY, S., et al., "Remediation of textile effluents by membrane based treatment techniques: A state of the art review", Journal of Environmental Management, $\mathrm{v}$. 147, pp. 55-72, 2015.

[2] AOUNI, A., FERSI, C., CUARTAS-URIBE, B., et al., "Reactive dyes rejection and textile effluent treatment study using ultrafiltration and nanofiltration processes”, Desalination, v. 297, pp. 87-96, 2012.

[3] BASHA, C. A., SENDHIL, J., SELVAKUMAR, K. V., et al., "Electrochemical degradation of textile dyeing industry effluent in batch and flow reactor systems", Desalination, v. 285, pp. 188-197, 2012.

[4] BALAMURUGAN, B., THIRUMARIMURUGAN, M., KANNADASAN, T. "Anaerobic degradation of textile dye bath effluent using Halomonas sp”, Bioresource Technology, v. 102, pp. 6365-6369, 2011.

[5] HARRELKAS, F., AZIZI, A., YAACOUBIB, A., et al., "Treatment of textile dye effluents using coagulation-flocculation coupled with membrane processes or adsorption on powdered activated carbon", Desalination, v. 235, pp. 330-339, 2009.

[6] IGNACHEWSKI, F., FUJIWARA, S. T., CÓTICA, L. F., et al., "Degradação de corantes reativos por

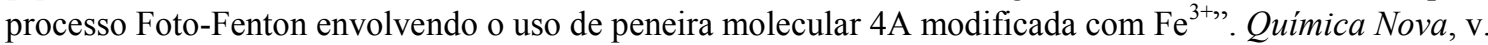
33, n. 8, pp. 1640-1645, 2010.

[7] CHAKRABORTY, S., DE, S., DASGUPTA, S., et al., "Adsorption study for the removal of a basic dye: experimental and modeling”, Chemosphere, v. 58, pp. 1079-1086, 2005.

[8] ALINSAFI, A., MOTTA, M., LEBONTÉ, S., et al., "Effect of variability on the treatment of textile dyeing wastewater by activated sludge", Dyes and Pigments, v. 69, pp. 31-39, 2006.

[9] CONCEIÇÃO, V., FREIRE, F. B., CARVALHO, K. Q. "Treatment of textile effluent containing indigo blue dye by a UASB reactor coupled with pottery clay adsorption”, Acta Scientiarum. Technology, v. 35, n. 1, pp. 53-58. 2013.

[10] SOUZA, C. R. L., PERALTA-ZAMORA, P. "Degradação de corantes reativos pelo sistema ferro metálico/peróxido de hidrogênio", Quim. Nova, v. 28, n. 2, pp. 226-228, 2005.

[11] ASAD, S., AMOOZEGAR, M. A., POURBABAEE, A. A., et al., "Decolorization of textile azo dyes by newly isolated halophilic and halotolerant bacteria", Bioresource Technology, v. 98, n. 11, pp. 2082-2088, 2007.

[12] LUANGDILOK, W., PANSWAD, T. "Effect of chemical structures of reactive dyes on color removal by an anaerobic-aerobic process", Water Science and Technology, v. 42, n. 3/4, pp. 377-382, 2000.

[13] RAJAGURU, P., KALAISELVI, K., PALANIVEL, M., et al., "Biodegradation of azo dyes in a sequential anaerobic-aerobic system”, Appl. Microbiol. Biotechnol., v. 54, n. 2, pp. 268-273, 2000.

[14] BROMLEY-CHALLENOR, K. C. A., KNAPP, J. S., ZHANG, Z., et al., "Decolorization of an azo dye by unacclimated activated sludge under anaerobic conditions", Water Research, v. 34, n. 18, pp. 4410-4418, 2000.

[15] KUDLICH, M., BISHOP, P. L., KNACKMUSS, H. J. et al., "Simultaneous anaerobic and aerobic degradation of the sulfonated azo dye mordant yellow 3 by immobilized cells from a naphatlenesulfonatedegrading mixed culture”, Appl Microbiol. Biotechnol., v. 46, pp. 597-603, 1996.

[16] ROBINSON, T., MCMULLAN, G., MARCHANT, R., et al., "Remediation of dyes in textile effluent: a critical review on current treatment technologies with a proposed alternative", Bioresource Technology, v. 77, pp. 247-255, 2001.

[17] BASERI, J. R., PALANISAMY, P. N., KUMAR, P. S. “Adsorption of basic dyes from synthetic textile effluent by activated carbon prepared from Thevetia peruviana", Indian Journal of Chemical Technology, v. 19, n. 5, pp. 311-321, 2012.

[18] DOMINGUINI, L., MENEGARO, D.A., MIGUEL, T.F., et al., "Use of ceramic wastes in adsorption of methylene blue dyee", Cerâmica, v. 60, n. 354, pp. 218-222, 2014.

[19] MENEGARO, D.A., MIGUEL, T.F., BETIOLI, A.M., et al., "Cinética de adsorção de azul de metileno por resíduos de cerâmica vermelha”, Rev. Técnico Científica (IFSC), v. 3, n. 1, pp. 704, 2012. 
[20] ASSOCIAÇÃO BRASILEIRA DE NORMAS TÉCNICAS. NBR 6465:1984 - Agregados Determinação da abrasão "Los Angeles", São Paulo, 1984.

[21] VINEETHA, M. N., MATHESWARAN, M., SHEEBA, K. N. "Photocatalytic colour and COD removal in the distillery effluent by solar radiation”, Solar Energy, v. 91, pp. 368-373, 2013.

[22] GARG, S. K., TRIPATHI, M., SINGH, S. K., et al., "Biodecolorization of textile dye effluent by Pseudomonas putida SKG-1 (MTCC 10510) under the conditions optimized for monoazo dye orange II color removal in simulated minimal salt medium", International Biodeterioration \& Biodegradation, v. 74, p. 2435, 2012.

[23] NAGEL-HASSEMER, M.E., CORAL, L.A., LAPOLLI, F.R. "Processo UV/ $\mathrm{H}_{2} \mathrm{O}_{2}$ como pós-tratamento para remoção de cor e polimento final em efluentes têxteis", Química Nova, v. 35, n. 5, pp. 900-904, 2012.

[24] NOVOTNÝ, C., SVOBODOVÁ, K., BENADA, O., et al., "Potential of combined fungal and bacterial treatment for color removal in textile wastewater", Bioresource Technology, v. 102, pp. 879-888, 2011.

[25] SANTOS, A. B., CERVANTES, F. J., VAN LIER, J. B. "Review paper on current technologies for decolourisation of textile wastewaters: perspectives for anaerobic biotechnology", Bioresource Technology, v. 98, pp. 2369-2385, 2007.

[26] ARAUJO, F. V. F., YOKOYAMA, L., TEIXEIRA, L. A. C. "Remoção de cor em soluções de corantes reativos por oxidação com $\mathrm{H}_{2} \mathrm{O}_{2} / \mathrm{UV}$ ”, Química Nova, v. 29, n. 1, p. 11-14, 2006.

[27] LAGERGREN, S. "On the theory of so-called adsorption dissolved substances", Kungliga Svenska Vetenskapsakademiens Handlingar, v. 24, n. 4, p. 1-39, 1898.

[28] VALDIVELAN, V., KUMAR, K. V. "Equilibrium, kinetics, mechanism, and process design for the sorption of methylene blue onto rice husk", Journal of Colloid and Interface Science, v. 286, pp. 90-100, 2005.

[29] HO, Y. S., McKAY, G. "The kinetics of sorption of basic dyes from aqueous solution by sphagnum moss peat", Can. J. Chem. Eng., v. 76, pp. 822-827, 1998.

[30] HO, Y. S., WASE, D. A. J., FORSTER, C. F. "Kinetic studies of competitive heavy metal adsorption by sphagnum moss peat", Environmental Technology, v. 17, pp. 71-77, 1996.

[31] VUOLO, J. H. Fundamentos da teoria dos erros. $2^{\mathrm{a}}$ edição. São Paulo, E. Blucher, 1996.

[32] SHIRZAD-SIBONI,M., JAFARI, S.J., GIAHI, O., KIM, I., LEE, S., YANG, J. "Removal of acid blue 113 and reactive black 5 dye from aqueous solutions by activated red mud", Journal of Industrial and Engineering Chemistry, v. 20, pp. 1432-1437, 2014.

[33] BAYRAK, Y., UZGÖR, R. "Removal of Remazol Black B Textile Dye from Aqueous Solution by Adsorption: Equilibrium and Thermodynamic Studies", Journal of Dispersion Science and Technology, v. 34, n. 6, pp. , 828-833, 2013.

[34] KADAM, A., LADE, H.S., PATIL, S.M., et al., "Low cost $\mathrm{CaCl}_{2}$ pretreatment of sugarcane bagasse for enhancement of textile dyes adsorption and subsequent biodegradation of adsorbed dyes under solid state fermentation", Bioresource Technology, v. 132, pp. 276-284, 2013.

[35] CARDOSO, N.F., PINTO, R.B., LIMA, E.C., et al., "Removal of remazol black B textile dye from aqueous solution by adsorption". . Desalination, v. 269, n. 1-3, pp.92-103, 2011.

[36] CONCEIÇÃO, V. M., FREIRE, F.B. "Descoloração de efluente têxtil sintético em reator UASB seguido de adsorção em bagaço de cana-de-açúcar”, Revista Tecnológica, v. 22, pp. 109-122, 2013.

[37] ELKADY, M. F., IBRAHIM, A. M., EL-LATIF, M. M. A. "Assessment of the adsorption kinetics, equilibrium and thermodynamic for the potential removal of reactive red dye using eggshell biocomposite beads", Desalination, v. 278, p. 412-423, 2011.

[38] VASQUES, A. R., SOUZA, S. M. A. G. U., WEISSENBERG, L., et al., "Adsorção dos corantes RO16, RR2 e RR141 utilizando lodo residual da indústria têxtil”, Eng. Sanit. Ambient., v. 16, n. 3, pp. 245-252, 2011.

[39] AÇIKYıLDıZA, M., GÜRSES, A., GÜNES, K., et al., "A comparative examination of the adsorption mechanism of anionic textile dye (RBY 3GL) onto the powdered activated carbon (PAC) using various the isotherm models and kinetics equations with linear and non-linear methods", Applied Surface Science, v. 354, pp. 279-284, 2015. 
SILVA, A.B.C.; ANDRADE, R.M.F.; FREIRE, F.B.; NAGALLI, A.; CARVALHO, K.Q.; PASSIG, F.H.; KREUTZ, C. revista Matéria, v. 22, n. $3,2017$.

[40] ELMOUBARKI, R., MAHJOUBI, F. Z., TOUNSADI, H., et al., “Adsorption of textile dye on raw and decanted Moroccan clays: Kinetics, equilibrium and thermodynamics”, Water Resources and Industry, v. 9, pp. 16-29, 2015. 